\title{
Papers
}

\section{Effect of joint crisis plans on use of compulsory treatment in psychiatry: single blind randomised controlled trial}

\author{
Claire Henderson, Chris Flood, Morven Leese, Graham Thornicroft, Kim Sutherby, George Szmukler
}

\begin{abstract}
Objective To investigate whether a form of advance agreement for people with severe mental illness can reduce the use of inpatient services and compulsory admission or treatment. Design Single blind randomised controlled trial, with randomisation of individual patients. The investigator was blind to allocation.

Setting Eight community mental health teams in southern England.

Participants 160 people with an operational diagnosis of psychotic illness or non-psychotic bipolar disorder who had experienced a hospital admission within the previous two years. Intervention The joint crisis plan was formulated by the patient, care coordinator, psychiatrist, and project worker and contained contact information, details of mental and physical illnesses, treatments, indicators for relapse, and advance statements of preferences for care in the event of future relapse. Main outcome measures Admission to hospital, bed days, and use of the Mental Health Act over 15 month follow up. Results Use of the Mental Health Act was significantly reduced for the intervention group, 13\% (10/80) of whom experienced compulsory admission or treatment compared with $27 \%$ $(21 / 80)$ of the control group (risk ratio $0.48,95 \%$ confidence interval 0.24 to $0.95, \mathrm{P}=0.028$ ). As a consequence, the mean number of days of detention (days spent as an inpatient while under a section of the Mental Health Act) for the whole intervention group was 14 compared with 31 for the control group (difference 16, 0 to $36, \mathrm{P}=0.04$ ). For those admitted under a section of the Mental Health Act, the number of days of detention was similar in the two groups (means 114 and 117, difference $3,-61$ to $67, \mathrm{P}=0.98$ ). The intervention group had fewer admissions (risk ratio $0.69,0.45$ to $1.04, \mathrm{P}=0.07$ ). There was no evidence for differences in bed days (total number of days spent as an inpatient) (means 32 and 36, difference 4, - 18 to $26, \mathrm{P}=0.15$ for the whole sample; means 107 and 83 , difference $-24,-72$ to $24, \mathrm{P}=0.39$ for those admitted).

Conclusions Use of joint crisis plans reduced compulsory admissions and treatment in patients with severe mental illness. The reduction in overall admission was less. This is the first structured clinical intervention that seems to reduce compulsory admission and treatment in mental health services.
\end{abstract}

\section{Introduction}

For patients receiving psychiatric treatment a joint crisis plan aims to empower the holder and to facilitate detection and treatment of relapse. ${ }^{1}$ It is developed by a patient together with mental health staff. Held by the patient, it contains his or her choice of information, which can include an advance agreement for treatment preferences for any future emergency, when he or she might be too unwell to express coherent views.

The format was developed after consultation with national user groups, interviews with organisations and individuals using crisis cards, ${ }^{2}$ and detailed development work with service users in south London. The results of the pilot study ${ }^{1}$ showed that (at 6-12 month follow up) $57 \%$ of participating patients felt more involved in their care, $60 \%$ felt more positive about their situation, $51 \%$ felt more in control of their mental health problem, and $41 \%$ were more likely to continue treatment. ${ }^{1}$ The plan may have direct and indirect effects: family doctors and carers may be able to react earlier to a relapse, while emergency department staff may make better decisions. Negotiating the content may clarify treatment issues and build consensus between patients and staff, potentially reducing future compulsory treatment and care.

Use of the Mental Health Act has increased in English mental health services. Data returned to the Department of Health show a $57 \%$ increase in civil cases of compulsory detention under the Mental Health Act 1983 between 1988 and 1998. Legal detention can have serious negative consequences for patients, including restricted access to travel visas and financial services. Current policy in England is towards greater involvement of patients as partners in care ${ }^{45}$ In the review of the Mental Health Act 1983, the Legislation Scoping Study Committee referred to the desirability of reducing compulsory treatment through the use of advance agreements; in the context of new mental health legislation to be introduced "the creation and recognition of advance agreements about care would greatly assist in the promotion of informal and consensual care." ${ }^{6}$

We evaluated the effectiveness of joint crisis plans at reducing use of inpatient services and objective coercion at and during admission.

\section{Methods}

\section{Setting}

We recruited patients in 2000 and 2001 from seven community mental health teams in south London and one in Kent. Catchment areas ranged from near the national average to relatively socially deprived. The proportion of black and ethnic minorities was between $10.5 \%$ and $37.6 \%$. Each team provided mental health care to adults with severe mental illness for their catchment areas during office hours, with differing local arrangements for out-of-hours crisis response.

The training pack for the development of a joint crisis plan can be found on $\mathrm{P}+$ bmj.com 


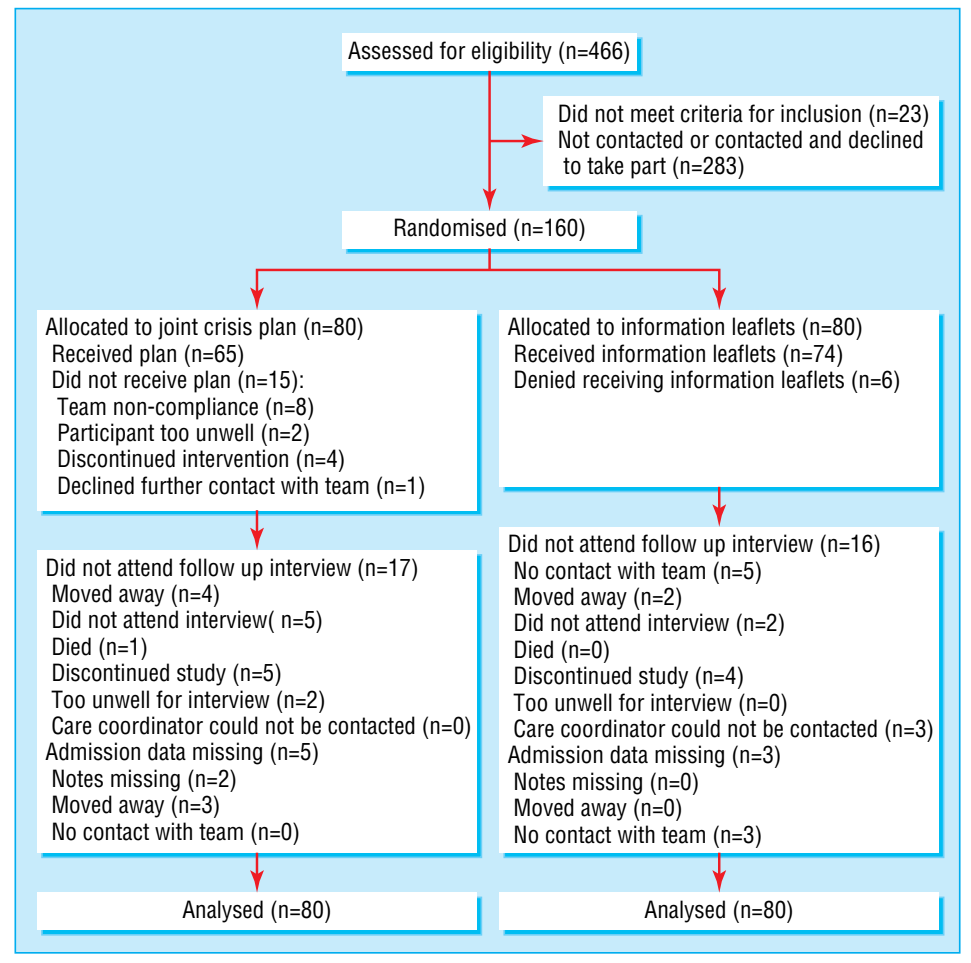

Trial profile: participant flow and follow up

\section{Participants}

A member of the community mental health team (either the consultant, the team secretary, or a community psychiatric nurse) provided a list of patients. All possible patients were on these lists. To be eligible, patients had to be in contact with their local community mental health team; have been admitted to a psychiatric inpatient service at least once in the previous two years; and have a diagnosis of psychotic illness or bipolar affective disorder without psychotic symptoms (according to the operational criteria checklist $^{7}$ ). We excluded those unable to give informed consent because of mental incapacity or insufficient command of English. Current inpatients were not recruited to avoid any coercion to participate. No other exclusions were made.

\section{Recruitment of participants and data collection}

Care staff arranged meetings for recruitment of participants and baseline interviews and were present at the meeting if they and the patient wished. All patients were informed about both arms of the trial and about the randomisation procedure. All participants gave written informed consent. One investigator $(\mathrm{CH})$ collected follow up data and was blinded to treatment group. The nature of the interventions meant that neither participants nor staff could be blinded to allocation.

Randomisation - Randomisation took place immediately after recruitment. The allocation sequence was generated by using minimisation, stratified by team and by severity of the patients' condition (necessitating standard versus enhanced level of care as defined by the CPA (care programme approach), to ensure even distributions of these features, which we expected would influence the production of the plan and its use by staff. Predictability of allocation by the minimisation process was occasionally a problem (when batches of similar patients were forwarded for allocation). To avoid this, ML reassigned the allocation of one patient, chosen at random, within each batch, before we reverted to minimisation. When a patient was recruited, the project worker requested allocation by email, which was returned by a statistician as intervention or control group. Allocation was not revealed to the investigator.

Intervention group-At the first meeting the project worker (CF) explained the procedure to the patient and, if possible, the care coordinator. To finalise each plan, the patient was encouraged to bring a carer, friend, or advocate to a second meeting. This meeting was to discuss the views of patients and professionals on what to do in a crisis and to negotiate agreed solutions. The selection of information to include and the exact wording were the patient's choice alone. Full details of how plans were produced are given in reports of our pilot study. ${ }^{2}$

Control group-Patients in the control group received information leaflets about local services, mental illness and treatments, the Mental Health Act, local provider organisations, and relevant policies. In accordance with standard practice in England, all patients should have received written copies of their care plan, within the care programme approach. ${ }^{8}$

Baseline and outcome measures-We collected data on sociodemographic variables, clinical details, history of adverse events-for instance, self harm and harm to others, and compliance with mental health treatment, rated by the care coordinator on a 7 point rating scale adapted for use with outpatients. ${ }^{9}$ Our primary outcomes were admission to hospital and length of time spent in hospital. Our secondary outcome was objective coercion-that is, compulsory treatment under the Mental Health Act 1983. We collected data on outcomes from case notes, the computerised patient administration system, Mental Health Act Office data, and interviews with patients and care coordinators. Follow up was conducted 15 months after randomisation.

\section{Sample size}

We calculated the required sample size from the pilot study using the proportion of patients admitted to psychiatric hospital at least once as the primary outcome, ${ }^{1}$. The proportion of the pilot sample admitted during one year fell from $70 \%$, averaged over 
Table 1 Adverse events in psychiatric patients randomised to receive joint crisis plan (intervention) or standard treatment (control). Figures are numbers (percentages) of patients

\begin{tabular}{|c|c|c|c|}
\hline & $\begin{array}{l}\text { Intervention group } \\
(\mathrm{n}=\mathbf{8 0})\end{array}$ & $\begin{array}{c}\text { Control group } \\
(\mathrm{n}=\mathbf{8 0})\end{array}$ & $P$ value * \\
\hline Declined further participation & $5(6)$ & $4(5)$ & 1.0 \\
\hline \multicolumn{4}{|l|}{ Self harm: } \\
\hline None & $73(99)$ & $69(91)$ & \multirow[t]{3}{*}{0.09} \\
\hline $\begin{array}{l}\text { Not resulting in admission or close } \\
\text { observations }\end{array}$ & $1(1)$ & $5(6)$ & \\
\hline $\begin{array}{l}\text { Resulting in admission or close } \\
\text { observations }\end{array}$ & $0(0)$ & $2(3)$ & \\
\hline \multicolumn{4}{|l|}{ Violence: } \\
\hline None & 71 (96) & 65 (85) & \multirow[t]{3}{*}{0.03} \\
\hline Not major† & $1(1)$ & $9(12)$ & \\
\hline Majorł & 2 (3) & $2(3)$ & \\
\hline
\end{tabular}

*Fisher's exact test.

†Incidents requiring attendance of police or seclusion on ward or special civil law admissions to place of safety.

tHomicide, sex attacks, attempted or actual serious assault.

the previous two years, to $45 \%$ during the year after the intervention. From these figures we calculated that at a significance level of $\mathrm{P}=0.05$ (double sided) and power of $80 \%$ required a sample size of 68 per group. We increased this to 76 (total 152) to allow for loss to follow up, estimated at $10 \%$ based on the rate of $7 \%$ at 6-12 months for the pilot study.

\section{Statistical analyses}

We compared age, sex, and length of contact with the service between those recruited and not recruited and baseline variables between the groups to establish if there were major differences. Patients discharged or transferred from the service were retained in their allocated group for intention to treat analyses. We used $\chi^{2}$ tests, $t$ tests, and non-parametric tests (Mann-Whitney) to compare the groups, the latter for bed days and number of days on a section (that is, compulsory detention for assessment or treatment under the Mental Health Act), both of which were skewed. We used Fisher's exact test to compare proportions of adverse events. Risk ratios (binary variables) and mean differences (continuous variables) and their 95\% confidence intervals were estimated, in the case of continuous variables, by bootstrapping 3000 replicates (bias corrected method). Stata version 8 was used for the analysis (StataCorp, College Station, TX). There were no interim analyses. All significance tests were double sided.

For use of the Mental Health Act, we compared numbers of patients subjected to any section and the number of days spent on a section per patient. We performed sensitivity analyses in which we repeated the analysis adjusting for any variables that were expected to be associated with the outcome variable-for instance, ethnicity, male sex, younger age, and compliance.

\section{Results}

\section{Participants}

We assessed 466 sets of case notes for eligibility using OPCRIT 5 (figure). ${ }^{7}$ There were no significant differences for age, sex, or length of service contact between eligible patients who were or were not recruited. Information on hospital admission was available for all participants. Bed days were available for all except one known admission. Information on use of the Mental Health Act was available for $77 / 80$ of each group (total $154 / 160=96 \%$ ) (figure). Of the 31 participants known to have been compulsorily admitted or treated, we knew the duration for each patient. One participant in the intervention group died from a longstanding
Table 2 Baseline demographic and clinical characteristics of participant groups. Figures are numbers (percentages) unless stated otherwise

\begin{tabular}{|c|c|c|}
\hline & $\begin{array}{l}\text { Intervention group } \\
\qquad(\mathrm{n}=\mathbf{8 0})\end{array}$ & $\begin{array}{l}\text { Control group } \\
(\mathrm{n}=80)\end{array}$ \\
\hline Mean (SD) age (years) & $39.5(12.1)$ & $38.6(10.6)$ \\
\hline Men & 47 (59) & $47(59)$ \\
\hline \multicolumn{3}{|l|}{ Country of birth: } \\
\hline UK & $48(60)$ & $43(54)$ \\
\hline Outside UK & $30(37)$ & $25(31)$ \\
\hline Missing & $2(2)$ & $12(15)$ \\
\hline \multicolumn{3}{|l|}{ Ethnic group: } \\
\hline White & $29(36)$ & $34(42)$ \\
\hline Black & $44(55)$ & $40(50)$ \\
\hline Other & 7 (9) & $6(7)$ \\
\hline \multicolumn{3}{|l|}{ Household composition: } \\
\hline Alone & $36(45)$ & $33(41)$ \\
\hline With family member(s) & $20(25)$ & $28(35)$ \\
\hline Others & $19(24)$ & $17(21)$ \\
\hline Missing & $5(6)$ & $2(2)$ \\
\hline Median (range) years of education & $11(8-18)$ & $11(9-20)$ \\
\hline Median No of previous psychiatric admissions & $5(n=75)$ & $5(n=69)$ \\
\hline $\begin{array}{l}\text { Days in psychiatric hospital in } 6 \text { months before } \\
\text { recruitment (median) }\end{array}$ & 29 & 42 \\
\hline \multicolumn{3}{|l|}{ Ever admitted on section: } \\
\hline Yes & $70(87)$ & $73(91)$ \\
\hline \multicolumn{3}{|l|}{ Ever had police involved in admission: } \\
\hline Yes & $48(60)$ & $37(46)$ \\
\hline No & $17(21)$ & $23(29)$ \\
\hline Not known & $15(19)$ & $20(25)$ \\
\hline \multicolumn{3}{|l|}{ History of self harm: } \\
\hline None & $53(66)$ & $45(56)$ \\
\hline Yes, not resulting in admission or observations & $5(5)$ & $6(7)$ \\
\hline Yes, resulting in admission or observations & $20(25)$ & $19(24)$ \\
\hline Missing & $2(2)$ & $10(12)$ \\
\hline \multicolumn{3}{|l|}{ History of violence: } \\
\hline None & $48(60)$ & $44(55)$ \\
\hline Not major* & $13(19)$ & $15(19)$ \\
\hline Major† & $17(21)$ & $12(15)$ \\
\hline Missing & $2(2)$ & $9(11)$ \\
\hline High current care programme approach $\ddagger$ & $71(89)$ & $70(88)$ \\
\hline Mean (SD) compliance rating & $4.8(1.3)$ & $4.9(1.3)$ \\
\hline
\end{tabular}

*Incidents requiring attendance of police or seclusion on ward or special civil law admissions to place of safety.

†Homicide, sex attacks, attempted or actual serious assault.

fDefined as having more than one member of the community mental health team involved in providing care as per the treatment plan.

cardiac condition. Table 1 shows other adverse events during follow up. Table 2 shows that the sociodemographic and clinical features of the two groups were similar.

\section{Hospital admissions}

Table 3 shows that a smaller proportion of the intervention group were admitted ( $30 \% v 44 \%$, risk ratio $0.69,95 \%$ confidence interval 0.45 to $1.04, \chi^{2}=3.25, \mathrm{P}=0.07$ ). There was no significant difference in mean bed days (difference $4,-18$ to $26, \mathrm{P}=0.15$, for the whole sample; difference $-24,-72$ to $24, \mathrm{P}=0.39$, for those admitted). Overall about a quarter of patients were admitted for more than one month $(23 \%$ in the intervention group and $29 \%$ in the control group).

\section{Use of the Mental Health Act}

Compulsory admission and treatment were significantly less common in the intervention group ( $13 \% v 27 \%$, risk ratio 0.48 , 0.24 to $0.95, \chi^{2}=4.84, \mathrm{P}=0.03$, table 3 ). Sensitivity analyses did not alter this conclusion. The mean number of days of detention for the intervention group was 14 compared with 31 for the control group (difference 17,0 to $36, \mathrm{P}=0.04$ ). For those admitted 


\begin{tabular}{|c|c|c|c|c|}
\hline & $\begin{array}{l}\text { Intervention } \\
\text { group }(\mathrm{n}=80)\end{array}$ & $\begin{array}{l}\text { Control group } \\
(\mathrm{n}=80)\end{array}$ & $\begin{array}{c}\text { Test } \\
\text { statistic* }\end{array}$ & $P$ value \\
\hline Missing data & 0 & 1 & - & - \\
\hline $\begin{array}{l}\text { No (\%) patient admitted at least } \\
\text { once }\end{array}$ & $24(30)$ & $35(44)$ & 3.25 & 0.07 \\
\hline \multicolumn{5}{|l|}{ Mean (median) No of bed dayst: } \\
\hline Whole sample & $32(0)$ & $36(0)$ & 1.52 & 0.15 \\
\hline Those admitted & $107(75)$ & $83(48)$ & 0.74 & 0.39 \\
\hline $\begin{array}{l}\text { No (\%) of patients with at least } \\
\text { one compulsory admission }\end{array}$ & $10(12.5)$ & $21(26.5)$ & 4.84 & 0.03 \\
\hline \multicolumn{5}{|c|}{ Mean (median) time on section (days): } \\
\hline Whole sample & $14(0)$ & $31(0)$ & 4.13 & 0.04 \\
\hline For those on section & $114(104)$ & $117(99)$ & 0.00 & 0.98 \\
\hline
\end{tabular}

${ }^{*} \chi^{2}$ values from Mann-Whitney tests, except proportions admitted or on section, which were from Pearson's $\chi^{2}$ tests.

tFor 34 participants in control group because of missing data.

on a section, the mean number of days on a section was similar in the two groups (difference $3,-61$ to $67, \mathrm{P}=0.98$ ).

The pattern of types of section was similar in both groups (table 4), but those in the intervention group were less likely to be put on a section (table 4) and more often had their sections terminated early (table 5).

\section{Discussion}

In this single blind randomised controlled trial of joint crisis plans for patients receiving psychiatric treatment, we have shown that a type of advance agreement significantly reduces use of the Mental Health Act both at and during hospital admission. Evidence that it can also reduce number of admissions was weaker, and there was no significant difference for number of bed days used.

\section{Methodological considerations}

This study has several important limitations. The rate of hospital admission among the control group was lower than expected from our pilot study, which reduced the power of the study to detect a difference in this outcome and resulted in wide confidence intervals for the mean differences in bed days, consistent with either an increase or a decrease in length of hospital stay. Only $36 \%$ of eligible patients agreed to participate, so the results may not be widely generalisable. Those who declined to participate when interviewed reported that the plan would not help them, they were unlikely to become ill again, that a plan was already in place, or that no one would take any notice of it. On the other hand, generalisability was strengthened by the various settings for recruitment (inner city, suburban, small town) and the broad ethnic representation of patients. The follow up rate for the outcomes reported was high.

Table 4 Sections of Mental Health Act used for intervention and control groups

\begin{tabular}{lccccccccc} 
Type of section* $^{*}$ & $\mathbf{5 . 2}$ & $\mathbf{2}$ & $\mathbf{3}$ & $\mathbf{4}$ & $\mathbf{1 3 5}$ & $\mathbf{1 3 6}$ & $\mathbf{3 7}$ & $\mathbf{0 t h e r}$ & Total \\
\hline Intervention group & 1 & 4 & 10 & 0 & 0 & 1 & 0 & 3 & 19 \\
\hline Control group & 8 & 6 & 19 & 1 & 0 & 1 & 1 & 1 & 37
\end{tabular}

* More than one Section may be applied per patient. Section 5.2 allows for detention while already in hospital for up to 72 hours. Sections 2, 3, and 4 allow compulsory admission to hospital depending on whether the application involves one (section 4) or two doctors (sections 2 and 3 ) and on whether admission is for up to 28 days' assessment (section 2) or for up to 6 months' treatment (section 3). Section 136 allows the police to remove someone to a place of safety from a public place, and section 135 allows them to do this from a person's home having obtained a warrant from a magistrate. Section 37 is a hospital order, which follows trial with psychiatric defence.

\begin{tabular}{|c|c|c|c|c|c|}
\hline Outcome & $\begin{array}{l}\text { Appealed } \\
\text { successfully }\end{array}$ & $\begin{array}{c}\text { Appealed } \\
\text { unsuccessfully }\end{array}$ & Lapsed & Rescinded & Converted \\
\hline Intervention group & 1 & 0 & 3 & 6 & 3 \\
\hline Control group & 1 & 1 & 2 & 16 & 2 \\
\hline
\end{tabular}

\section{Implications for services}

The reduction in use of the Mental Health Act has important implications for mental health services. Although the provision of a written care plan, signed by the patient, is now required in England, the joint crisis plan is substantially different. Making a joint crisis plan is voluntary, while the standard care plan is a statutory requirement. Thus, joint crisis plans can be used only when staff and patients want to formulate and use them. Furthermore, a third party, with knowledge of severe mental health problems and who is not a team member, mediates between the parties in producing each joint crisis plan. Such facilitation requires extra resources. The joint crisis plan is therefore different from a self completed advance directive ${ }^{10}$ because it is fully agreed with staff, increasing the likelihood that it will be implemented.

Finally, the process of writing a joint crisis plan is deliberately one of negotiation. We intend to undertake further investigation in future to understand what such negotiation means for staff and patients, to explore the power relationships between staff and patients, and to investigate more fully other contextual factors which may impact on such a complex intervention. ${ }^{10-15}$ We can find no other evidence in the literature that a structured clinical intervention can significantly reduce compulsory psychiatric admission and treatment. This study suggests that the committee reviewing the Mental Health Act 1983 was correct in its assertion that advance agreements can promote more consensual and less coercive care. ${ }^{6}$

We thank all participants, their informal carers, and care staff for their help in conducting the study.

Contributors: CH, CF, ML, GT, GS, and KS designed and performed the study. CH and ML did the statistical analysis. GT is the guarantor.

Funding: CH was supported by a Medical Research Council training fellowship in health services research, and CF was supported by a South London and Maudsley Trust health services research committee grant.

Competing interests: None declared.

\section{What is known already on this topic}

The use of advance agreements and directives for mental health care are advocated by groups for service users and voluntary sector organisations but there has been no evidence for their effectiveness so far

Rates of use of the Mental Health Act 1983 have been rising in England since it was introduced

\section{What this study adds}

An advance agreement made between staff and a person with a severe mental illness, negotiated by a third party, can lead to a considerable reduction in compulsory admission and treatment

This is the first time that a structured clinical intervention has been shown to reduce compulsory admission and treatment in adult mental health services 
Ethical approval: Ethics Committees of the South London and Maudsley NHS Trust, Lewisham University Hospital, South West London and Saint George's NHS Trust, and Thames Gateway NHS Trust.

1 Sutherby K, Szmukler GI, Halpern A, Alexander M, Thornicroft G, Johnson C, et al. A study of "crisis cards" in a community psychiatric service. Acta Psychiatr Scand $1999 ; 100: 56-61$.

2 Sutherby K, Szmukler GI. Crisis cards and self-help crisis initiatives. Psychiatric Bulletin 1998;22:4-7.

3 Department of Health. Inpatients formally detained in hospitals under the Mental Health Act 1983 and other legislation, England: 1988-89 to 1998-99. London: Government Statistical Service, 1999.

4 Department of Health. The national service framework for mental health. Modern standards Department of Health. The national service framework for
and service models. London: Department of Health, 1999.

5 Department of Health. The NHS plan. London: Department of Health, 2000

6 Department of Health. Report of the expert committee. Review of the Mental Health Act 1983. London: Stationery Office, 1999

7 McGuffin P, Farmer A, Harvery I. A polydiagnostic application of operational criteria in studies of psychotic illness. Development and reliability of the OPCRIT System. Arch Gen Psychiatry 1991;48:764-70.

8 Department of Health. Effective care co-ordination in mental health services. Modernising the care programme approach. A policy booklet. London: Department of Health, 2000.

9 Kemp RA, Lambert TJ. Insight in schizophrenia and its relationship to psychopathology. Schizophr Res 1995;18:21-8.

10 Papageorgiou A, King M, Janmohamed A, Davidson O, Dawson J. Advance directives for patients compulsorily admitted to hospital with serious mental illness: randomised controlled trial. BrJ Psychiatry 2002;181:513-9.
11 Campbell M, Fitzpatrick R, Haines A, Kinmonth AL, Sandercock P, Spiegelhalter D, et al. Framework for design and evaluation of complex interventions to improve health.

12 Medical Research Council. A framework for development and evaluation of RCTs for complex interventions to improve health. London: Medical Research Council, Health Services and Public Health Research Board, 2000.

13 Pawson R, Tilley N. Realistic evaluation. London: Sage Publications, 1997.

14 Thomas P. How should advance statements be implemented? (letter). Br J Psychiatry 2003; 182:548-9.

15 Bracken P, Thomas P. Postpsychiatry: a new direction for mental health. BMJ 2001;322:724-7.

(Accepted 6 May 2004)

doi $10.1136 /$ bmj. 38155.585046 .63

Health Services Research Department, Institute of Psychiatry, King's College London, London SE5 8AF

Claire Henderson MRC special training fellow in health services research

Chris Flood research assistant

Morven Leese statistician

Graham Thornicroft professor of community psychiatry

South London and Maudsley NHS Trust, Croydon CR0 1XT

Kim Sutherby consultant psychiatrist

Institute of Psychiatry, King's College London, London

George Szmukler dean

Correspondence to: C Henderson hendersc@nypdrat.cpmc.columbia.edu 